\title{
A Rare Complication in Ultrasound-guided Supraclavicular Brachial Plexus Block
}

\author{
${ }^{1}$ Sindil Kumar Sahu, ${ }^{2}$ Usha Badole
}

\section{ABSTRACT}

Orthopaedic upper limb surgeries are commonly performed under brachial plexus block. Ultrasound guidance significantly improves the quality of nerve block with lesser number of complications, although complications cannot be eliminated completely. Ipsilateral recurrent laryngeal nerve palsy is a rare complication associated with supraclavicular approach. We report a case of 28 year old female who developed hoarseness of voice following ultrasound guided supraclavicular brachial plexus block. The diagnosis of ipsilateral recurrent laryngeal nerve palsy requires a high index of suspicion and it should always be kept in differential diagnosis when a patient develops hoarseness of voice or respiratory compromise after supraclavicular brachial plexus block.

Keywords: Recurrent laryngeal nerve palsy, Supraclavicular brachial plexus block, Ultrasound guidance.

How to cite the article: Sahu SK, Badole U. A Rare Complication in Ultrasound-guided Supraclavicular Brachial Plexus Block. Res Inno Anaesth 2016;1(1):30-31.

\section{Source of support: Nil}

Conflict of interest: None

\section{INTRODUCTION}

Supraclavicular brachial plexus block is commonly performed for upper limb surgeries. Intravascular injection, pneumothorax, hemidiaphragmatic paresis, cervical sympathetic block, and nerve injury are the common complications with this approach. Recurrent laryngeal nerve palsy is a rare complication associated with this approach (1\% incidence) ${ }^{1}$ although cases have been documented with interscalene approach. Nowadays, use of ultrasound guidance (USG) has made the blocks more accurate and reduced the rate of complications. But complications cannot be eliminated completely, even with the use of USG.

\footnotetext{
${ }^{1}$ Speciality Medical Officer, ${ }^{2}$ Professor

${ }^{1,2}$ Department of Anaesthesia and Critical Care, Grant Government Medical College and Sir JJ Hospital, Mumbai Maharashtra, India

Corresponding Author: Sindil Kumar Sahu, Speciality Medical Officer, Department of Anaesthesia, Hinduhridaysamrat Balasaheb Thackeray Medical College and Dr RN Cooper Municipal General Hospital, Juhu, Mumbai, Maharashtra, India, Phone: +918108817667, e-mail: sindil0712@gmail.com
}

\section{HISTORY}

A 28-year-old American Society of Anesthesiologists grade I female presented with fracture of right distal end radius for plating. A successful right supraclavicular brachial plexus block was given with $35 \mathrm{ml}$ of $0.25 \%$ bupivacaine under USG. Within 5 minutes, she developed hoarseness of voice and bouts of cough. In next 15 minutes, hoarseness and cough became more severe. With the exception of mild tachycardia (90-100/ $\mathrm{min}$ ), her vitals (blood pressure and arterial oxygen saturation, $\mathrm{SpO}_{2}$ ) were stable. A gentle laryngoscopy was done under sedation with propofol, as recurrent laryngeal nerve involvement was suspected. On laryngoscopy, the right vocal cord was found immobile and abducted. In view of progressive symptoms and to secure airway, patient was electively intubated after giving induction dose of propofol $(2 \mathrm{mg} / \mathrm{kg})$ and inj. succinyl choline $(2 \mathrm{mg} / \mathrm{kg})$. Ultrasound examination of supraclavicular fossa was done again, which ruled out vascular injury or hematoma (Fig. 1).

Intraoperatively, intravenous injection of hydrocortisone $100 \mathrm{mg}$ and dexamethasone $8 \mathrm{mg}$ was given. Surgery was completed in 2 hours. Patient was extubated and observed in recovery room. Her cough had subsided, but hoarseness of voice persisted. Postoperative x-ray of the chest was done, which was absolutely normal (no pneumothorax and no unilateral diaphragm elevation). Injection of dexamethasone $8 \mathrm{mg}$ twice-daily was continued for 5 days and patient was followed up for 7 days in the ward. The hoarseness gradually subsided over the next 48 hours.

After 48 hours, indirect laryngoscopy (IDL) using $70^{\circ}$ scope confirmed right vocal cord mobility, but it was not coming till midline (Fig. 2).

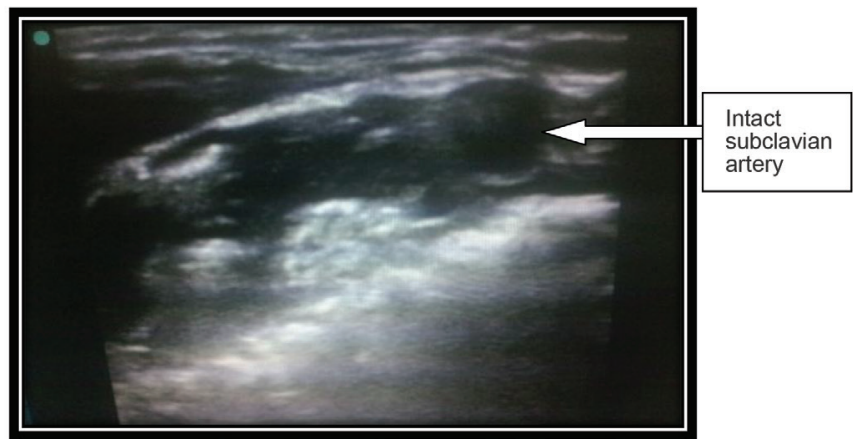

Fig. 1: Ultrasound guidance picture of right supraclavicular fossa 


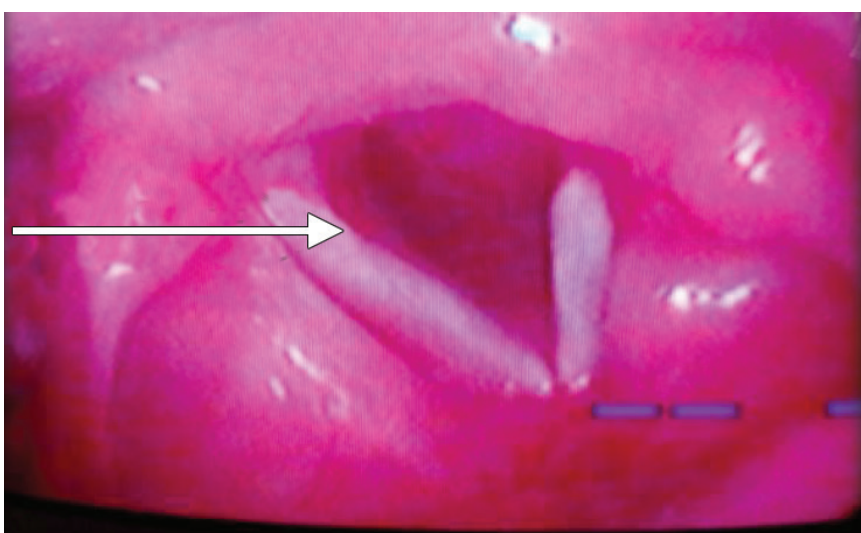

Fig. 2: Indirect laryngoscopy after 48 hours

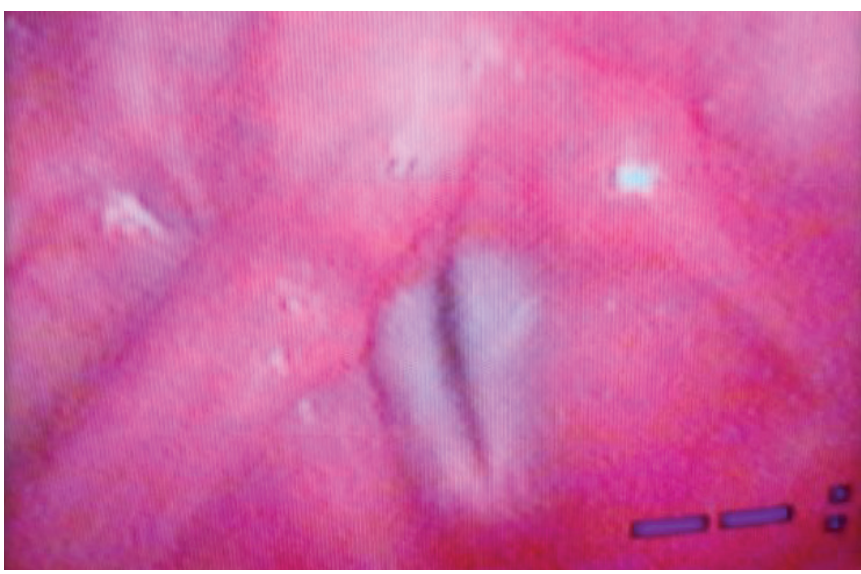

Fig. 3: Indirect laryngoscopy on the 5th day

Indirect laryngoscopy was normal on the 5th day (Fig. 3).

\section{DISCUSSION}

Hoarseness of voice and cough suggest possibilities of recurrent laryngeal nerve block, allergic reaction to local anesthetic, pneumothorax, or bronchospasm. Factors going in favor of right recurrent laryngeal nerve palsy are right vocal cord immobility and abduction on direct laryngoscopy, stable vitals (only mild tachycardia), maintenance of saturation before and after intubation, decreased mobility of right vocal cord on IDL (after 48 hours), and normal right vocal cord mobility on IDL (after 5 days). Also, there was no evidence of pneumothorax and hemidiaphragmatic elevation (phrenic nerve palsy) on postoperative $\mathrm{x}$-ray of the chest.

Recurrent laryngeal nerve provides vocal cord adduction that is necessary for airway protection and modification of phonation through the thyroarytenoid and lateral cricothyroid. ${ }^{2}$ A unilateral recurrent laryngeal nerve lesion may have clinical manifestations of hoarseness of voice, cough, dysphonia, dyspnea, aspiration, or more rarely may be asymptomatic. ${ }^{3}$ Recurrent laryngeal nerve paralysis after a brachial plexus block is a rare but well-documented complication. Ward ${ }^{4}$ described 1 (3\%) incident of right-sided recurrent laryngeal nerve palsy out of 34 consecutive patients receiving an interscaleneapproach brachial plexus block for upper extremity procedures. Hickey et $\mathrm{al}^{5}$ described $2(1.3 \%)$ incidents of right-sided recurrent laryngeal nerve palsy out of 156 consecutive patients receiving a subclavian perivascular block for upper extremity procedures. Although recurrent laryngeal nerve involvement is theoretically possible on either side, hoarseness has been reported after brachial plexus blocks only on the right, most likely because the injected anesthetic can travel along the subclavian artery to the position where the nerve loops under the vessel. ${ }^{6}$

\section{CONCLUSION}

Ipsilateral recurrent laryngeal nerve palsy can occur even with supraclavicular approach. In a patient with a preexisting contralateral vocal cord paralysis, recurrent laryngeal nerve palsy can create an airway emergency. Before performing a brachial plexus block, a thorough preoperative evaluation for vocal cord paralysis should be stressed, especially in patients who have undergone any type of neck surgery or received radiation treatment to the neck or upper chest.

\section{REFERENCES}

1. Neal, JM. Upper extremity blocks. Rathmell, JP., editor. Regional anesthesia: the requisites in anesthesiology. 1st ed. Philadelphia: Elsevier Mosby; 2004. p. 59-72.

2. Sasaki CT, Weaver EM. Physiology of the larynx. Am J Med 1997 Nov24;103(5A):9S-18S.

3. Kraus DH, Ali MK, Ginsberg RJ, Hughes CJ, Orlikoff RF, Rusch VW, Burt ME, McCormack PM, Bains MS. Vocal cord medialization for unilateral paralysis associated with intrathoracic malignancies. J Thorac Cardiovasc Surg 1996 Feb;111(2): 334-341.

4. Ward ME. The interscalene approach to the brachial plexus. Anesthesia 1974 Mar;29(2):147-157.

5. Hickey R, Garland TA, Ramamurthy S. Subclavian perivascular block: influence of location of paresthesia. Anesth Analg 1989 Jun;68(6):767-771.

6. Winnie, AP. Plexus anesthesia. Vol 1. Perivascular techniques of brachial plexus block. 2nd ed. Philadelphia: WB Saunders; 1990. p. 236-237. 